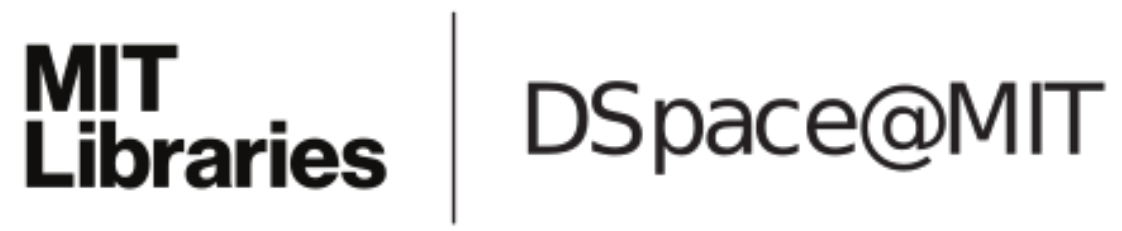

\author{
MIT Open Access Articles
}

On the maximum pressure rise rate in boosted $\mathrm{HCCl}$ operation

The MIT Faculty has made this article openly available. Please share how this access benefits you. Your story matters.

Citation: Wildman, Craig, Robert J. Scaringe, and Wai Cheng. "On the Maximum Pressure Rise Rate in Boosted HCCl Operation." presented at SAE 2009 Powertrains Fuels and Lubricants Meeting, November 2009, San Antonio, TX, USA, SAE International, 2009.

As Published: http://dx.doi.org/10.4271/2009-01-2727

Publisher: SAE International

Persistent URL: http://hdl.handle.net/1721.1/66887

Version: Author's final manuscript: final author's manuscript post peer review, without publisher's formatting or copy editing

Terms of use: Creative Commons Attribution-Noncommercial-Share Alike 3.0 


\title{
On the Maximum Pressure Rise Rate in Boosted HCCl Operation
}

\author{
Craig Wildman, Robert J. Scaringe, Wai Cheng \\ Massachusetts Institute of Technology
}

Copyright ( 2009 SAE International

\begin{abstract}
This paper explores the combined effects of boosting, intake air temperature, trapped residual gas fraction, and dilution on the Maximum Pressure Rise Rate (MPRR) in a boosted single cylinder gasoline $\mathrm{HCCl}$ engine with combustion controlled by negative valve overlap. Dilutions by both air and by cooled EGR were used. Because of the sensitivity of MPRR to boost, the MPRR constrained maximum load (as measured by the NIMEP) did not necessarily increase with boosting. At the same intake temperature and trapped residual gas fraction, dilution by recirculated burn gas was effective in reducing the MPRR, but dilution by air increased the value of MPRR. The dependence of MPRR on the operating condition was interpreted successfully by a simple thermodynamic analysis that related the MPRR value to the volumetric heat release rate.
\end{abstract}

\section{INTRODUCTION}

While gasoline Homogeneous Charge Compression Ignition $(\mathrm{HCCl})$ engines could offer substantial gain in fuel economy, the operating domain is rather limited compared to the drive train requirement $[1,2]$. There is, therefore, substantial interest in widening the range of operation. Boosting is one option to extend the high load limit [2-6]. Because of Noise-Vibration-andHarshness (NVH) and engine durability concerns, however, the maximum pressure rise rate (MPRR) posts a severe limitation on the high load limit of $\mathrm{HCCl}$ engines. This constrain is especially pronounced under boosted operation because of the higher energy density of the charge and the increase of chemical reaction rate with fuel and air concentrations.
This paper explores the combined effects of boosting, intake air temperature, trapped residual gas fraction, and dilution on MPRR in a single cylinder gasoline engine equipped with electromagnetically activated intake and exhaust valves so that trapped residual gas was controlled by negative valve overlap. Dilutions by both air and by cooled EGR were used. The boost was generated by a motor driven compressor; the exhaust was throttled so that the exhaust and intake pressure were approximately equal. The purpose of this work was not to design or calibrate an engine to reach the highest load, but rather, to assess the dependence of the MPRR on the various engine parameters.

\section{ENGINE SET UP}

The single cylinder engine with electromagnetic variable valve timing (EVVT) has been described previously [1]. The engine was based on a Ricardo Hydra Diesel crankcase and a Volkswagen TDI engine head (Model year 2001). A small racing car spark plug (NGK R84711) was mounted in the original fuel injector hole and a Kistler 6125 pressure transducer was mounted in the original glow-plug hole. To accommodate the boosted operation, the compression ratio was lowered (by inserting a spacer between the head and the block) to 10.2 to avoid severe knocking in both the $\mathrm{SI}$ and $\mathrm{HCCl}$ modes under boosted operation. The engine specifications are listed in Table 1.

Table 1: EM Valve Engine

Bore

Stroke

$80.26 \mathrm{~m}$

$88.9 \mathrm{~mm}$

Connecting rod $\quad 158 \mathrm{~mm}$

Displacement $\quad 449.8 \mathrm{cc}$

Compression ratio $\quad 10.2$

Fuel UTG91

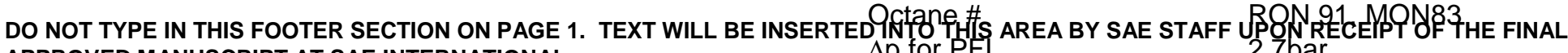
APPROVED MANUSCRIPT AT SAE INTERNATIONAL. 
The fuel (a calibration gasoline, UTG91 from Chevron Philips, with $\mathrm{RON}=91, \mathrm{MON}=83$ ) was introduced by port fuel injection at an injection pressure differential of 2.7 bar.

Because it was difficult to obtain a production turbocharger for a small single cylinder engine, and that substantial calibration would be needed for the matching of the turbo-charger and the engine characteristics, the boosted operation was simulated by using an externally driven compressor. The compressor was a production supercharger (the one used by the BMW MiniCooper vehicle for a $1.6 \mathrm{~L}$ engine) driven by an electric motor. The arrangement is shown in Fig. 1. The compressor discharge was water-cooled by a heat exchanger. Most of the discharge was by-passed back to the compressor in a loop; the flow to the engine was controlled by throttling this by-pass loop.

The flow into the engine comprised a branch of the cooled compressor air flow as described above, and an external Exhaust Gas Recirculation (EGR) flow. To enable the latter, a close loop controlled exhaust throttle was used to maintain an exhaust pressure slightly higher (by 0.03 bar) than the Manifold Absolute Pressure (MAP). The EGR flow was controlled by a throttle valve.

The EGR flow was water cooled. Care was taken to ensure that the temperature was above the dew point to prevent water condensation. The cooled compressed air was reheated and mixed with the EGR flow. The heating power was controlled to maintain a targeted intake mixture temperature into the engine.

\section{DIRECT MEASUREMENT OF TRAPPED BURNED GAS MOLE FRACTION}

An important parameter for assessing the engine operation is the amount of total trapped burned gas, which comprises the external EGR and the internal residual. The amount of EGR flow relative to the compressed air flow was determined by measuring the $\mathrm{CO}_{2}$ concentrations at the two points indicated in Fig. 1. The total burned gas mole fraction before combustion, $\mathrm{x}_{\mathrm{burn}}$, was determined by measuring the time resolved incylinder $\mathrm{CO}_{2}$ mole fraction with a fast-response $\mathrm{CO}_{2}$ analyzer (Cambustion Model NDIR 500).

Measurement of $x_{\text {burn }}$ is illustrated in Fig. 2. In the figure, the values $a$ and $b$ are the $\mathrm{CO}_{2}$ mole fractions of the charge before and after combustion. Thus

$a=\frac{N_{E G R} x_{C O 2, \text { burn }}+N_{\text {residual }} x_{C O 2, \text { burn }}}{N_{\text {air }}+N_{\text {fuel }}+N_{E G R}+N_{\text {residual }}}$

$\mathrm{b}=\mathrm{x}_{\mathrm{cO}, \mathrm{burn}}$

Here $\mathrm{N}$ denotes the number of moles of the subscripted quantities and $x_{\mathrm{CO} 2 \text {, burn }}$ is the mole fraction of $\mathrm{CO}_{2}$ in the combustion product. Combining Eqs. (1) and (2):

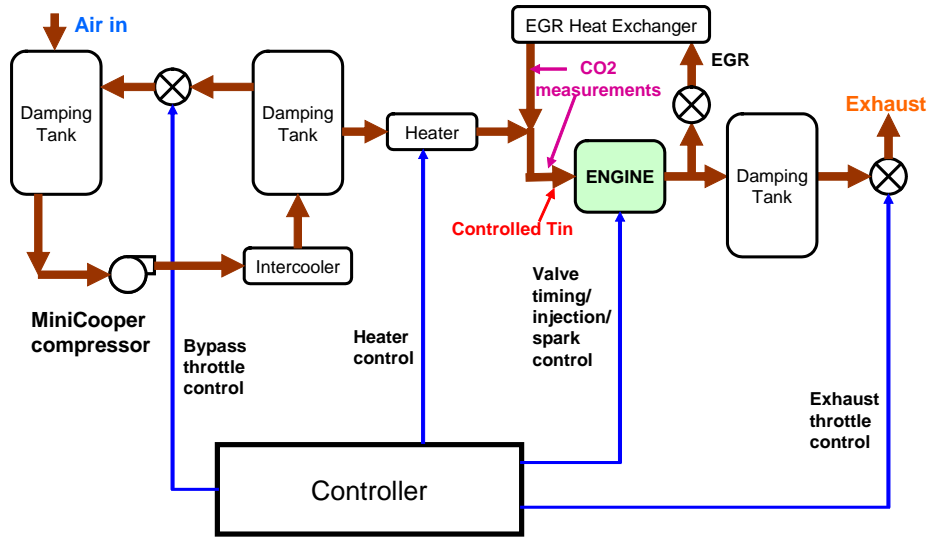

Fig.1 Engine set up for boosted operation with EGR.

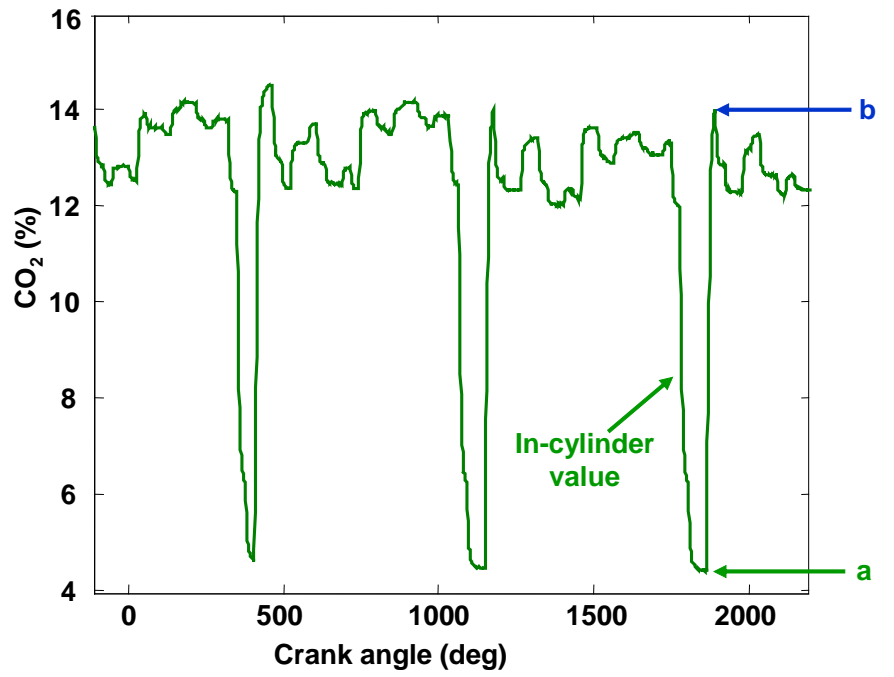

Fig.2 In-cylinder time-resolved $\mathrm{CO} 2$ measurement by fast-response $\mathrm{CO}_{2}$ analyzer.

$$
\mathrm{X}_{\text {burn }}=\frac{\mathrm{N}_{\mathrm{EGR}}+\mathrm{N}_{\text {residual }}}{\mathrm{N}_{\text {air }}+\mathrm{N}_{\text {fuel }}+\mathrm{N}_{\mathrm{EGR}}+\mathrm{N}_{\text {residual }}}=\frac{\mathrm{a}}{\mathrm{b}}
$$

\section{INDIRECT DETERMINATION OF TRAPPED BURNED GAS MOLE FRACTION}

While the above method was a direct measurement of $x_{\text {burn }}$, the implementation of such for every measurement was difficult (e.g. the in-cylinder probe would plug up from time to time). We therefore, sought an indirect determination of $x_{\text {burn }}$ and verified these values with those from the direct method.

The mole of trapped residual may be calculated from the charge pressure and temperature at EVC.

$$
\mathrm{N}_{\text {residual }}=\left(\frac{\mathrm{PV}}{\mathrm{RT}}\right)_{\mathrm{EVC}}
$$

In practice, however, accurate in-cylinder pressure measurement at EVC was difficult because of transducer 
sensitivity, drift, and exhaust system pressure wave phenomenon. The charge temperature was difficult to measure directly. The exhaust pressure and temperature, however, were monitored. We therefore approximated Eq. (4) by the following:

$\mathrm{N}_{\text {residual }}=\left(\frac{\mathrm{P}_{\text {exh }} \mathrm{V}}{R T_{\text {exh }}}\right)_{\text {EVC }}$

Since the flows of air, fuel, and EGR were known (the latter obtained by the previously described external $\mathrm{CO} 2$ measurement), the values of $x_{\text {residual }}$ and $x_{\text {burn }}$ may be calculated from Eqs. (5) and (3).

Comparisons of the $\mathrm{x}_{\text {residual }}$ values obtained by the direct and indirect methods are shown in Fig. 3. There was very good agreement $-T_{\text {exh }}$ probably under estimated the trapped residual gas temperature; the $P_{\text {exh }}$ probably under estimated the trapped residual pressure; the two errors compensated for each other.

\section{$\mathrm{NO}_{\mathrm{X}}$ CONSIDERATION}

To investigate whether the $\mathrm{HCCl}$ engine would be able to meet the NOx emission requirement without a 3-way catalyst, and therefore, be permissible for lean operation, the effect of dilution on NOx emission under boosted condition was examined by using an engine simulation at $1500 \mathrm{rpm}$ and at various loads. Homogeneous combustion with a specified heat release profile typical of the $\mathrm{HCCl}$ combustion was used. The combustion phasing was at MBT timing.

Stoichiometric burned gas (i.e. operating at $\lambda=1$ ) was employed as the diluent to build the most optimistic case. (If air were used as the diluent in the simulation, there would be more NOx emission because the charge would be hotter due to the higher specific heat ratio and that more oxygen would be available for NO formation). The PZEV requirement of $0.02 \mathrm{~g} / \mathrm{mile}$ of NOx was used as the threshold. At the current CAFE level of $27.5 \mathrm{mpg}$, the corresponding NOx specific emission is $0.19 \mathrm{~g} / \mathrm{kg}$ fuel.

The engine-out NOx as a function of the diluent mole fraction is shown in Fig. 4 [7]. The specific NOx emission as a function of the diluent fraction was approximately independent of the level of boosting. To satisfy the PZEV requirement, more than $70 \%$ of diluent is required. At this high level of dilution, the combustion would not be stable, and even if good combustion could be achieved, the dilution would have substantially displaced the air so that NIMEP would be severely limited; see Fig. 5.

It is therefore concluded that to have reasonable NIMEP levels for $\mathrm{HCCl}$ high load operation, it is imperative that a 3-way catalyst be used. Thus the mixture must be at stoichiometric $(\lambda=1)$.

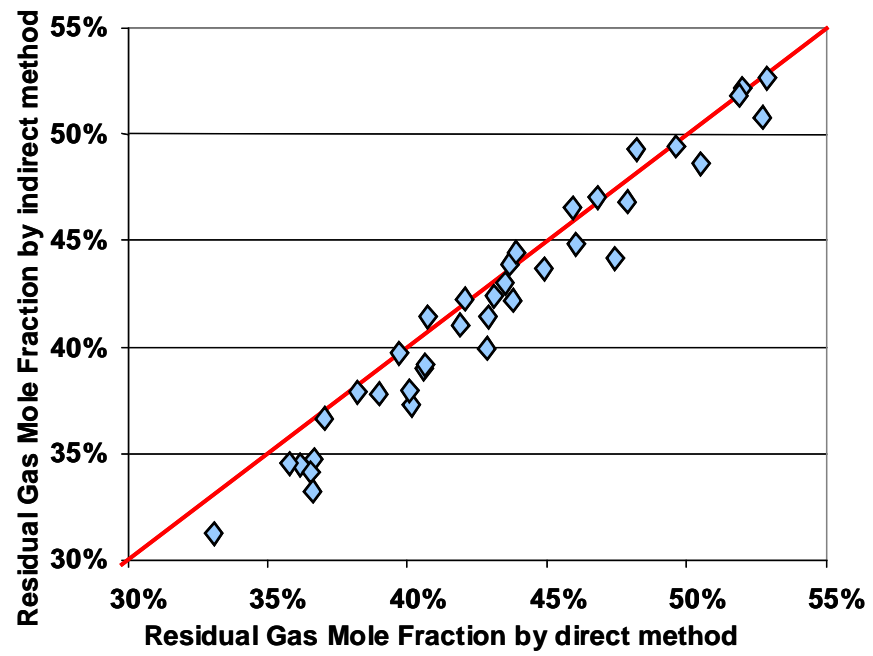

Fig. 3 Comparison of the trapped residual fraction ( $\left.\mathrm{x}_{\text {residual }}\right)$ obtained by the indirect (Eq.5) and direct (Eq. 3) methods. Data encompass operation at MAP $=1.1$ and 1.3 bar. Extent of NVO was used to vary residual trapping.

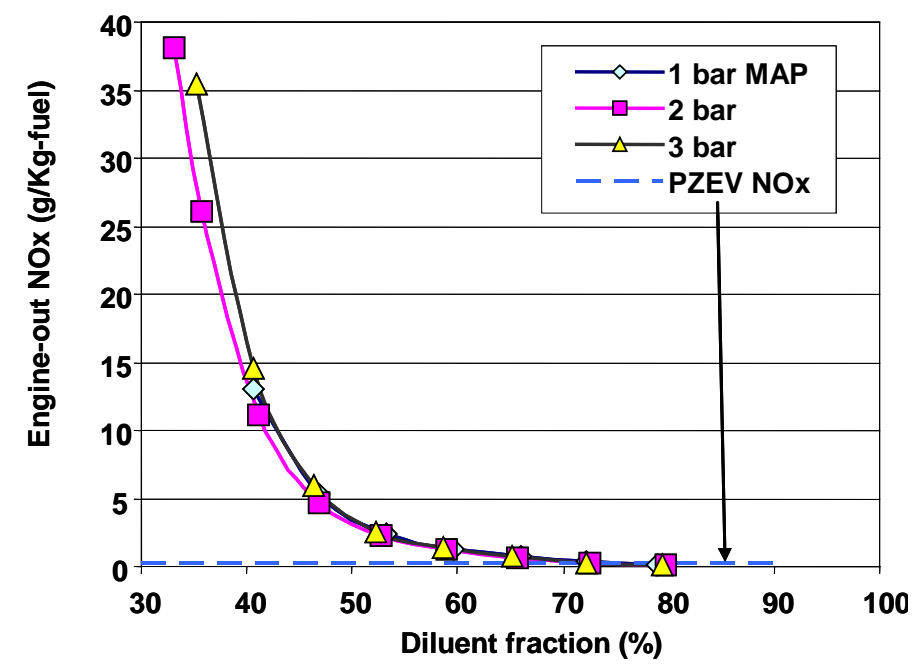

Fig. 4 Specific NOx emission as a function of diluent mole fraction; from $\mathrm{HCCl}$ engine simulation at $1500 \mathrm{rpm}$ with NVO; $\lambda=1$; from Ref. [7]

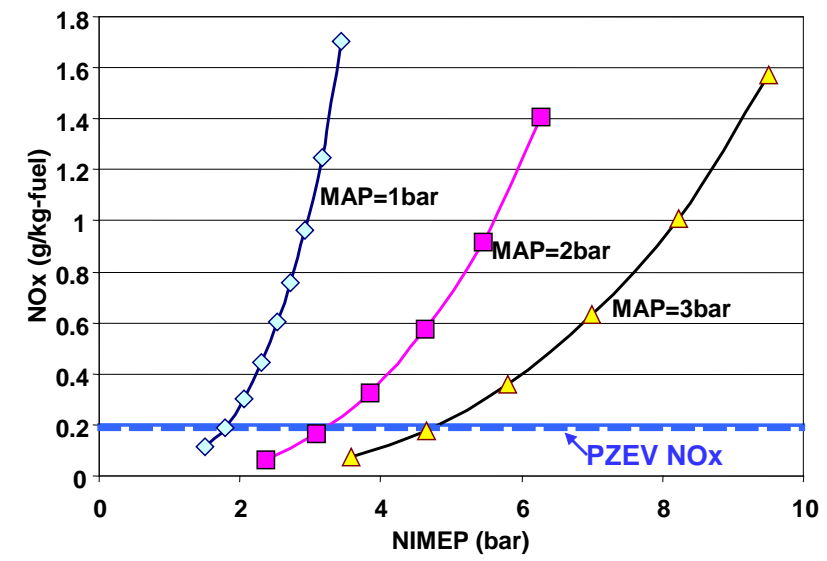

Fig. 5 Same plot as Fig. 4, except $X$-axis is replaced by the NIMEP values. To satisfy the PZEV requirement without catalyst, the range of NIMEP permissible is very limited; from Ref. [7] 
Most of our data were obtained at $\lambda=1$; however, to assess the effect of dilution by air on combustion, we also ran experiments at $\lambda>1$.

\section{NVH METRIC}

Several metrics used to measure the $\mathrm{NVH}$ from the combustion pressure oscillation are shown in Table 2. Also shown are the scaling of the metric with the pressure and its rise rate, and the scaling with MEP. The MPRR is most widely used because it is simple and easily obtainable from engine data. The criterion for onset of pressure oscillation [8] is deemed not appropriate for $\mathrm{HCCl}$ combustion in which pressure oscillations have often been observed without significant audible knock [10]. The ringing index (RI) is based on the acoustic energy flux produced by the oscillating charge pressure $[9]^{1}$, and is increasingly being used in the literature.

It should be noted that MPRR is proportional to $\dot{\mathrm{p}}$ and RI is proportional to $\dot{\mathrm{p}}^{2} / \mathrm{p}$; thus both values scale with MEP. We have chosen to use MPRR over RI as the metric because MPRR is readily available from the data while the maximum temperature required for the RI calculation needs to be estimated. For our data, there was a close correspondence between MPRR and RI so that the choice of the metric was almost immaterial; see Fig. 6 . A reasonable MPRR limit of $5 \mathrm{MPa} / \mathrm{ms}$ [10] was used in this work. The value of MPRR was calculated as the average over many cycles of the individual cycle-value of $(\mathrm{dp} / \mathrm{dt})_{\max }$; see Ref.[10] for details.

\section{TEST MATRIX}

All the data were taken at engine speed of $1500 \mathrm{rpm}$. The valve timing strategy is shown in Fig. 7 . The NVO, of half angle $\theta_{0}$, is symmetric with respect to TDCexhaust. The exhaust pressure was kept equal to MAP +0.03 bar. The controlling parameters are MAP, intake mixture temperature $T_{i}$, and the NVO half angle $\theta_{0}$. All data were taken at $\lambda=1$ except when noted. Dilution with external EGR and with air (then $\lambda>1$ ) were used.

The test matrix comprised temperature sweeps at MAP $=1.01,1.25$ and 1.5 bar with fixed $\theta_{0}=75^{\circ}$, sweeps of NVO and MAP (1 to 1.6 bar) at $T_{i}=30$ to $120^{\circ} \mathrm{C}$, and dilution at 5 and 10 mole \% with air and with EGR.

\section{GENERAL DATA TREND}

At fixed NVO, $\lambda=1$,.and with no EGR, the effects of intake temperature $\left(T_{i}\right)$ and MAP on NIMEP, MPRR, CA50 and $10-90 \%$ burn duration are shown in Fig. 8.

\footnotetext{
${ }^{1}$ In Ref.[9], $\beta$ was set to $0.05 \mathrm{~ms}$, which corresponds to $f$ $=5 \mathrm{KHz}$. In general the $\beta$ value should be adjusted according to $f$.
}

Table 2: NVH Metric

\begin{tabular}{|l|l|c|c|}
\hline \multicolumn{1}{|c|}{ Basis } & \multicolumn{1}{|c|}{ Metric } & $\begin{array}{c}\dot{\mathrm{p}} \text { and } \mathbf{p} \\
\text { scaling }\end{array}$ & $\begin{array}{c}\text { Scaling } \\
\text { with } \\
\text { MEP }\end{array}$ \\
\hline $\begin{array}{l}\text { MPRR } \\
\text { (Widely } \\
\text { used) }\end{array}$ & $\dot{\mathrm{p}}$ & $\dot{\mathrm{p}}$ & $\propto$ MEP \\
\hline $\begin{array}{l}\text { Pressure } \\
\text { oscillation } \\
\text { onset [8] }\end{array}$ & $\begin{array}{l}{\left[\frac{\dot{p}}{\mathrm{p}} \frac{(\mathrm{r} / \mathrm{a})}{3 \gamma}\right]_{\text {local }} \quad \text { where } \mathrm{r} \text { is }} \\
\text { the size of the fast heat } \\
\text { release region and a the } \\
\text { sonic velocity }\end{array}$ & $\frac{\dot{p}}{\mathrm{p}}$ & Neutral \\
\hline $\begin{array}{l}\text { Acoustic } \\
\text { energy } \\
\text { flux [9] }\end{array}$ & $\begin{array}{l}\text { Ringing index }(\mathrm{RI}) \\
=\frac{\sqrt{\gamma \mathrm{R}^{*} T_{\max }}}{2 \gamma \mathrm{P}_{\max }}\left[\beta(\dot{\mathrm{p}})_{\max }\right]^{2} \\
\text { where } \beta \approx 1 /(4 \mathrm{f}) \text { and } \mathrm{f} \text { is } \\
\text { the oscillation frequency }\end{array}$ & $\frac{\dot{\mathrm{p}}^{2}}{\mathrm{p}}$ & $\propto \mathrm{MEP}$ \\
\hline
\end{tabular}

The NIMEP increased with MAP due to more fuel was burned; decreased with $T_{i}$ because of the lower volumetric efficiency. The MPRR increased with MAP because more energy was released and because of earlier combustion phasing (see CA50 data in the next

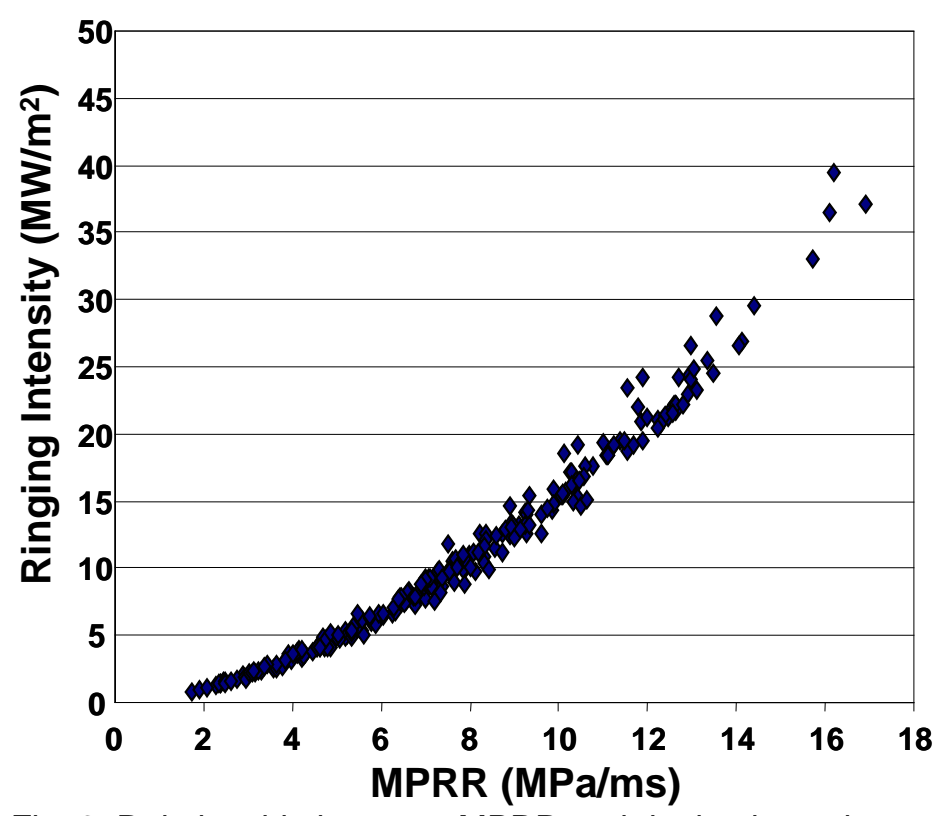

Fig. 6 Relationship between MPRR and ringing intensity. Data encompass MAP of 1 to 1.5 bar, various residual fractions; $1500 \mathrm{rpm}$.

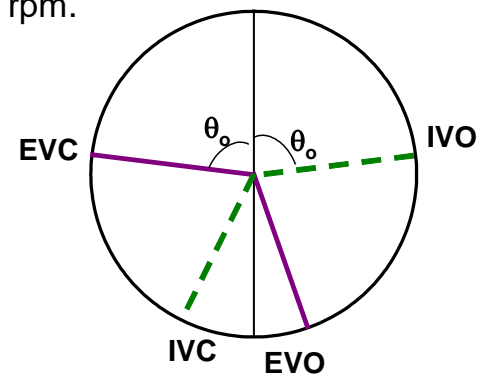

Fig.7 Valve timing strategy: IVC fixed at $29^{\circ} \mathrm{ABC}$ compression; EVO fixed at $15^{\circ} \mathrm{BBC}$-expansion; NVO symmetric about TDC exhaust; NVO half angle is $\theta_{0}$. 
plot); the latter also explains the MPRR increase with $T_{i}$.

The combustion phasing, as depicted by CA50 in Fig. 8, advanced with both MAP and $T_{i}$. This observation could be explained by the temperature and pressure dependence of the ignition delay.

The 10-90\% burn duration also decreased with both MAP and $T_{i}$, although at the higher MAP values (1.25 and 1.5 bar), the burn duration did not change appreciably at $\mathrm{T}_{\mathrm{i}}>60^{\circ} \mathrm{C}$.

The NIMEP as a function of the fuel mass per cycle for all the data is shown in Fig. 9. The different operating temperatures were depicted by the symbol colors and the different intake temperatures by the symbol shapes. The data points with dilution by both air and EGR were included but not explicitly marked. The NIMEP was proportional to the fuel mass; the spread of the data was due to the different net indicated fuel conversion efficiency $\left(\eta_{\mathrm{f}, \mathrm{i}}\right)$ values, which were approximately in the range of 25 to $30 \%$. The lines of constant $\eta_{\mathrm{f}, \mathrm{l}}$ are also shown on Fig. 9.

The MPRR values were plotted versus NIMEP for the same set of data points in Fig. 10. There is a substantial data scatter, although it could be argued that there is a trend that MPRR increased with NIMEP. This data will be further analyzed in a later section with a simple thermodynamic analysis to collapse the data. Note that the MPRR values for most of the data were higher than the threshold level of $5 \mathrm{MPa} / \mathrm{ms}$.

\section{DILUTION EFFECTS}

Dilution is often used as a means to mitigate MPRR. However, because dilution reduces the energy density of the charge, the NIMEP would decrease from that obtained with a stoichiometric charge without dilution. Therefore, we compared the operations at the same level of total dilution (as mole fractions), both with external EGR and with air as "displacement" of the residual; see Fig. 11. In all cases, the intake was heated so that the intake temperatures of the mixtures were maintained at the target temperatures. Thus, referring to Fig. 11 for the three cases (subscripts $0=$ no dilution, 1 = EGR dilution, and $2=$ air dilution) at the same level of total dilution, the fuel amount were the same, whence the trapped burned gas temperatures were about the same. The diluent temperatures were both at $\mathrm{T}_{\mathrm{i}}$; thus the trapped charge temperatures of the EGR and air dilution were the same, while that of the no dilution case was higher because of the higher trapped enthalpy of the residual.

In the following, the case for dilution at $T_{\text {in }}=120^{\circ} \mathrm{C}$, MAP $=1.3$ bar, and $10 \%$ dilution (i.e., mole of EGR or excess air equaled to $10 \%$ of the mole of stoichiometric mixture) will be discussed. Data for other intake temperatures and MAP values behave similarly; see
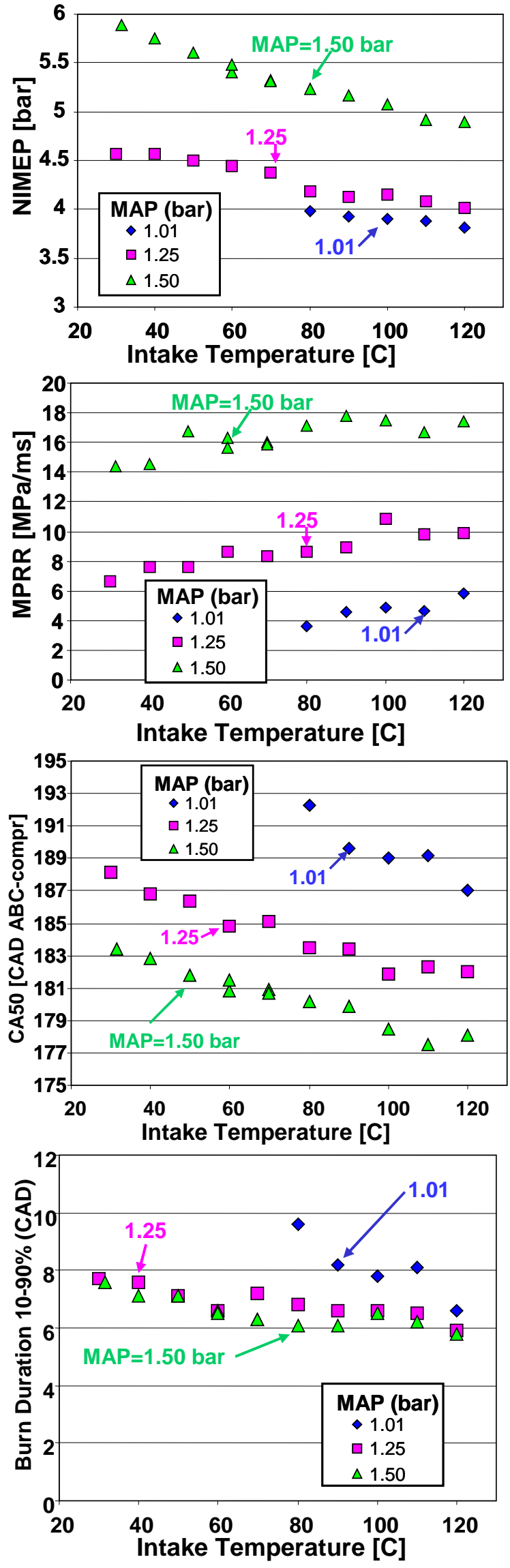

Fig. 8 General dependence of NIMEP, MPRR, CA50 and $10-90 \%$ burn duration on MAP and $\mathrm{T}_{i} ; 1500 \mathrm{rpm} ; \lambda=1$; no EGR; NVO half angle $\theta_{0}=75^{\circ}$. 


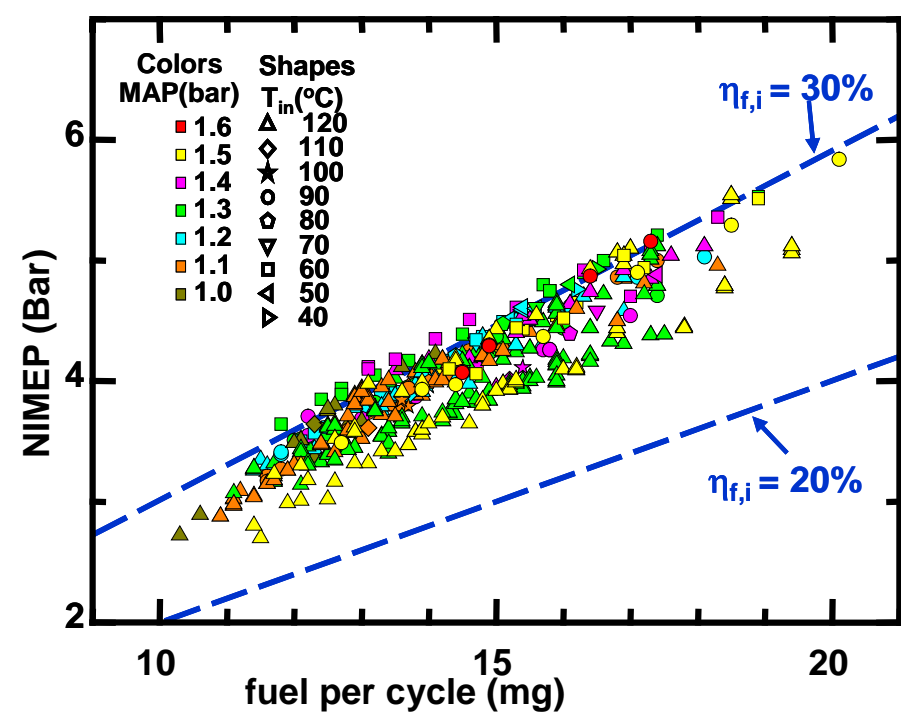

Fig. 9 NIMEP as a function of the fuel mass per cycle. The colors and symbols represent different operating conditions. The dilution data with both EGR and air were included but not explicitly marked.

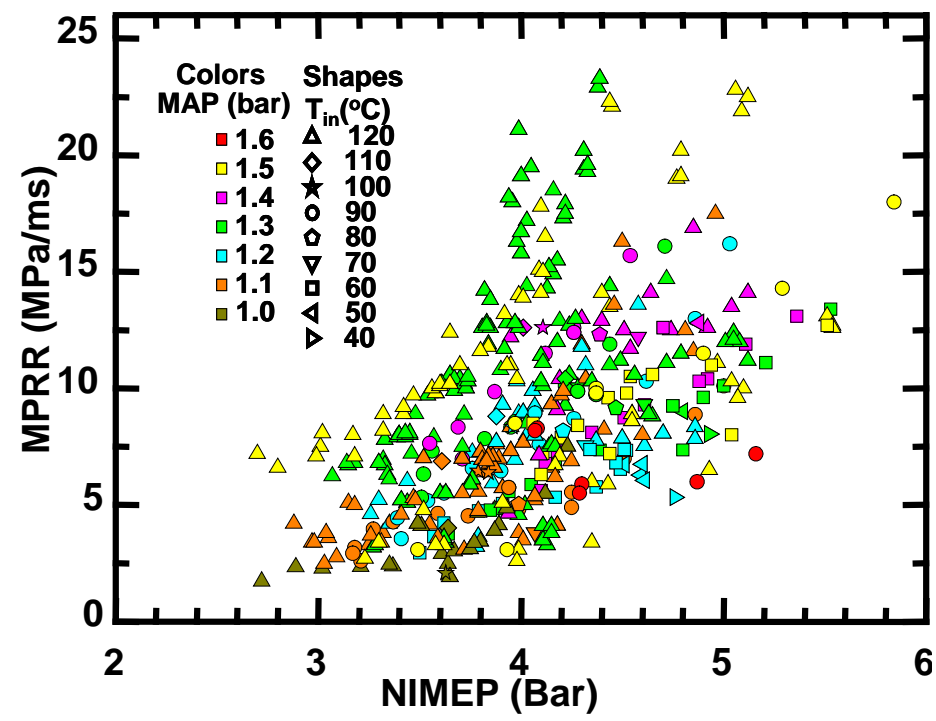

Fig. 10 MPRR versus NIMEP for the data points described in Fig. 9.

Appendix A. It should be noted that for the air dilution case, because of the presence of excess air in the residual gas, the averaged $\lambda$ in cylinder is higher than the metered $\lambda$ value.

The NIMEP values decreased with the increase of total dilution; see Fig. 12. The differences between the no external dilution (the stoichiometric, no egr case), dilution with egr and with air were due to the differences in indicated fuel conversion efficiencies because of changes in combustion phasing and burn duration (these data will be discussed later).

With no EGR or air dilution, the MPRR values decreased with increase of total dilution because less fuel was

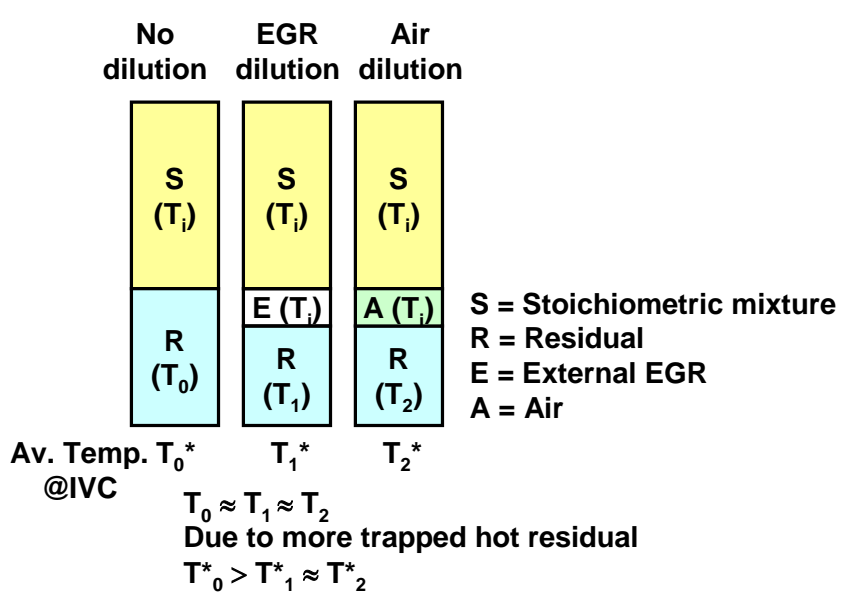

Fig. 11 Schematic of the dilution strategy at same level of dilution (all values in moles). A stoichiometric mixture was either diluted by EGR or by air; note that there was air in the residual for the latter case.

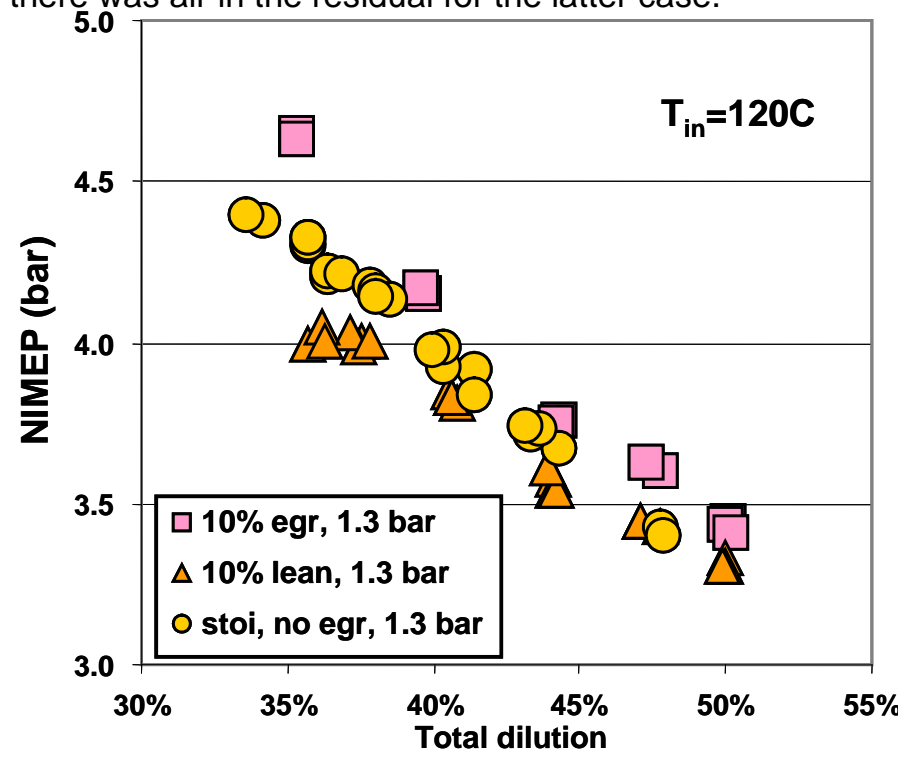

Fig. 12 Effect of total dilution on NIMEP. Engine at 1500 rpm; MAP $=1.3$ bar; $. T_{i}=120^{\circ} \mathrm{C} ; \lambda=1.0$ for $10 \%$ EGR case; $\lambda=1.1$ for $10 \%$ lean case.

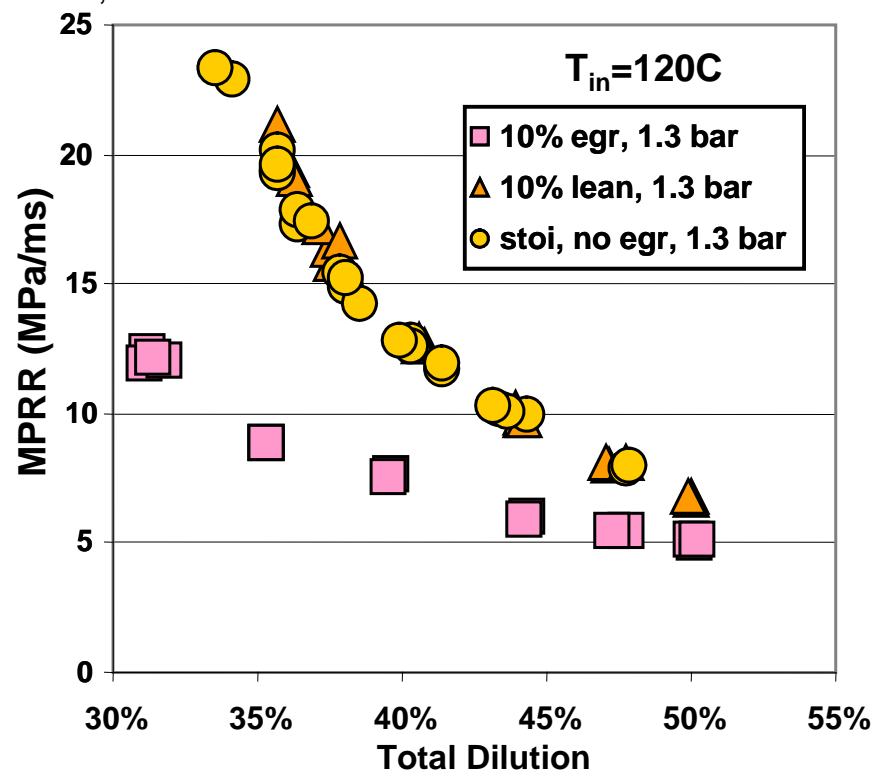

Fig. 13 Effect of total dilution on MPRR. See Fig. 12 caption for operating conditions. 


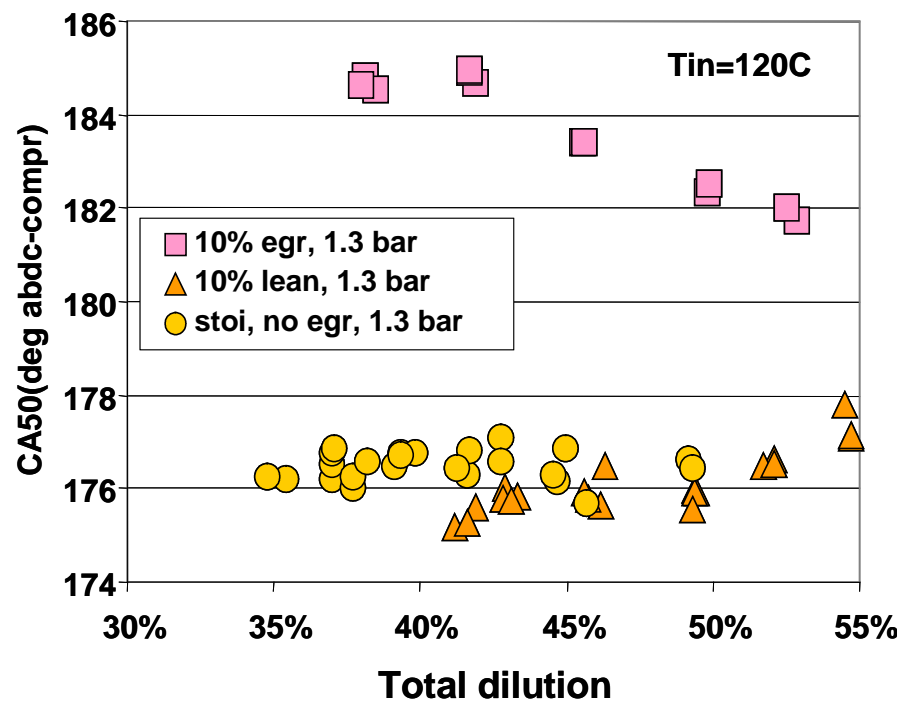

Fig. 14 Effect of total dilution on combustion phasing, as measured by CA50. See Fig. 12 caption for operating conditions.

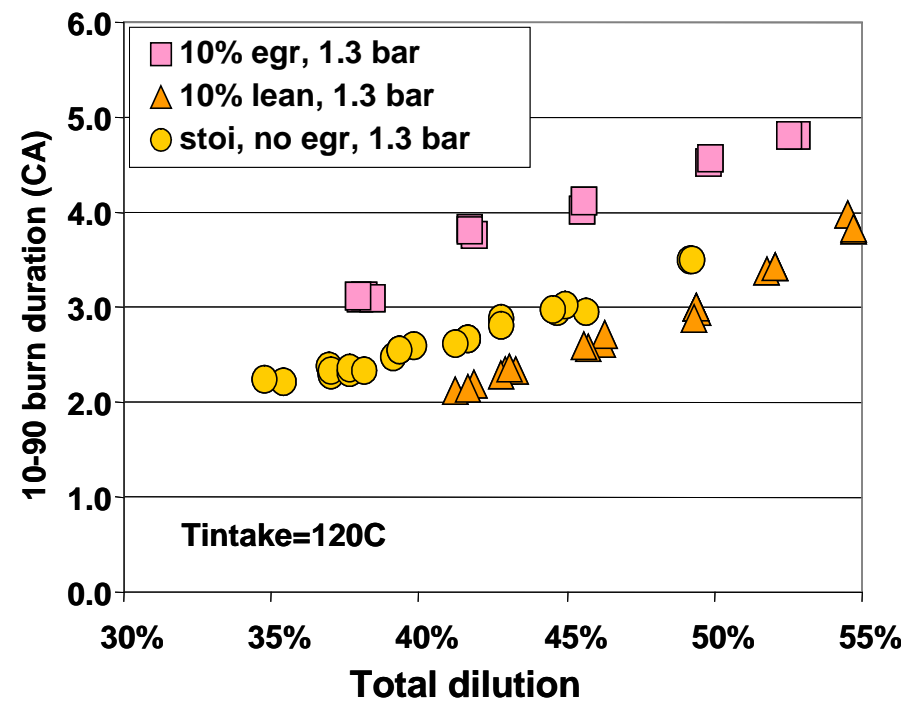

Fig. 15 Effect of total dilution on burn duration. See Fig. 12 caption for operating conditions.

burned; see Fig. 13. At the same total dilution, 10\% EGR substantially reduced the MPRR, although the effectiveness decreased with increase of total dilution. Dilution with $10 \%$ air, however, did not produce any change in the MPRR value.

The combustion phasing (as measured by CA50) and 10-90\% burn duration are shown in Fig. 14 and 15. At the same total dilution, CA 50 was substantially retarded and the burn duration lengthened by $10 \%$ external EGR. These two observations could explain the lower MPRR values obtained with EGR.

The dilution with air, however, did not produce substantial change in CA50 and burn duration compared to the no external dilution case. The CA50 values were actually slightly more advanced, and the burn duration slightly shortened.

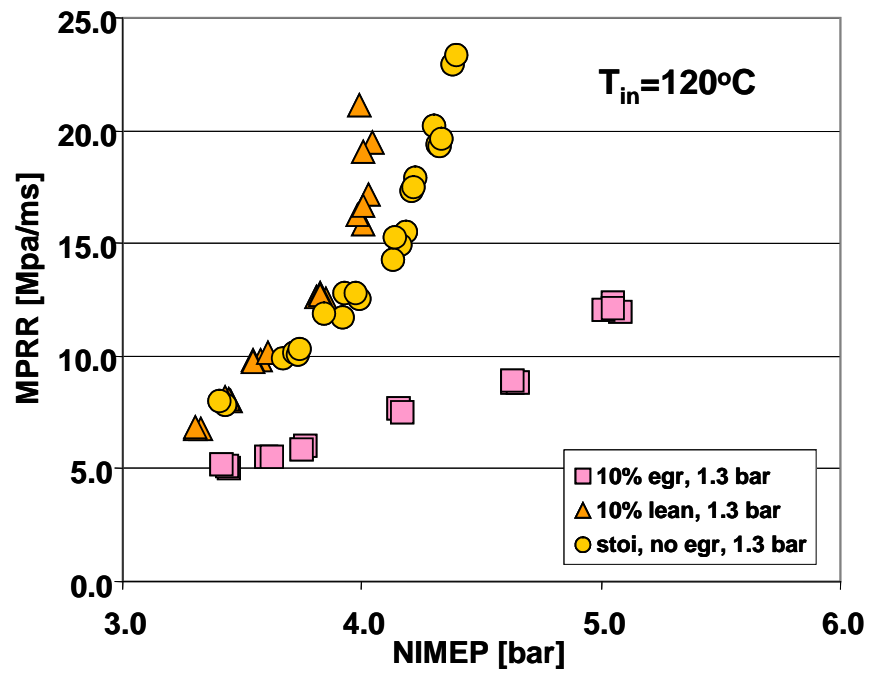

Fig. 16 MPRR versus NIMEP showing effect of dilution. See Fig. 12 caption for operating conditions.

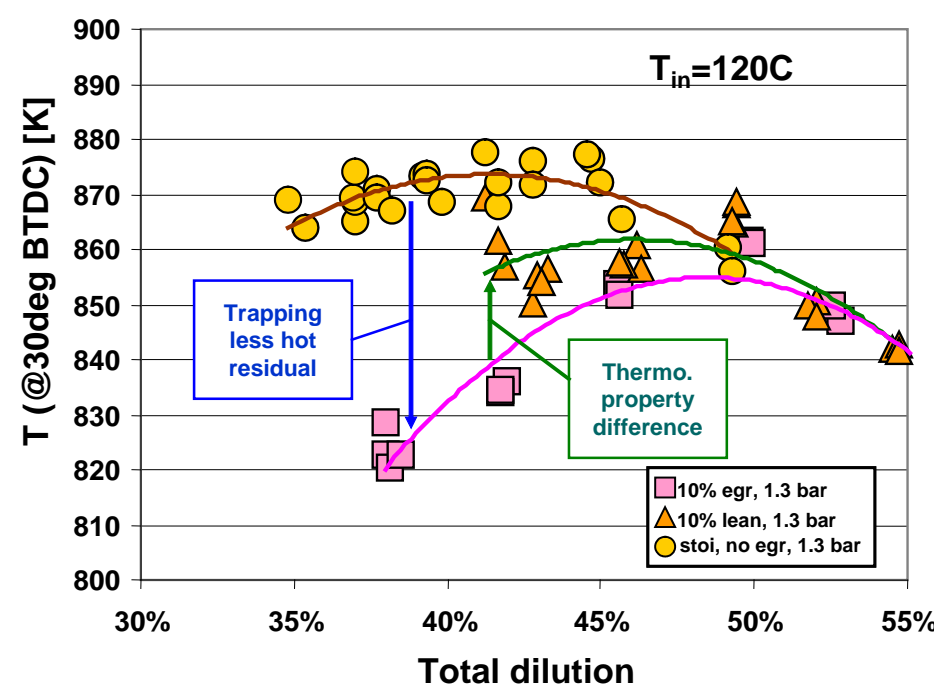

Fig. 17 Effect of dilution with EGR and with air on the preignition compression temperature. See Fig. 11 caption for operating conditions.

Fig. 16 shows MPRR versus NIMEP for the three cases. At the same output NIMEP, dilution by EGR was very effective in reducing MPRR. Dilution by air, however, was detrimental - it would make the MPRR values higher.

The external dilutions by EGR and by air affected both the operating temperature. For the latter case, the charge composition also changed because of the presence of excess oxygen. The temperature effect was assessed by examining the compression temperature $T_{c}$ (as the charge temperature at $30^{\circ} \mathrm{BTC}$-compression, at which there was negligible heat release). This temperature was computed from the pressure data and the total charge moles with the residual moles obtained via Eq. (3) or Eq. (5).

The result is shown in Fig. 17. For the no external dilution case, $T_{c}$ first increased with increase of total dilution (comprised only of internal residual) because 
more burned gas was trapped; it then decreased when the dilution was above approximately $42 \%$ because of the decrease in burned gas temperature.

With 10\% EGR, the trapped enthalpy decreased, and $T_{c}$ decreased correspondingly. This decrease in charge temperature, while the charge composition was approximately the same, was responsible for the retarded and slower combustion.

With $10 \%$ air dilution, $\mathrm{T}_{\mathrm{c}}$ was higher than that at $10 \%$ EGR dilution due to the higher charge specific heat ratio. It is noted, however, that at the same dilution level, Tc was still lower than that obtained with no external dilution. Therefore the advance in combustion and decrease in burn rate depicted in Figures 14 and 15 could not be solely attributed to a temperature effect. These observations are thus attributed to the presence of excess oxygen in the mixture which overrode the effect of a lower temperature (compared to the no external dilution case) and shortened the both the ignition delay and burn duration

It could be concluded from the above discussion that to mitigate MPRR, operating with external EGR at stoichiometric condition should be the strategy. Lean operation would only increase the MPRR at the same NIMEP.

\section{THERMODYNAMIC ASSESSMENT OF MPRR}

To understand the factors contributing to MPRR, a simple thermodynamic model is used. From energy balance, the pressure rise rate is

$$
\dot{\mathrm{p}}=(\gamma-1)\left[\dot{\mathrm{q}}-\frac{\dot{\mathrm{Q}}_{\mathrm{L}}}{\mathrm{V}}\right]-\left(\gamma \mathrm{P} \frac{\dot{\mathrm{V}}}{\mathrm{V}}\right)
$$

To assess the maximum pressure rise rate at the high load limit, the heat lost term $\dot{\mathrm{Q}}_{\mathrm{L}} N$ and the volumetric expansion term $\left(2^{\text {nd }}\right.$ term on the right-hand-side $)$ are small compared to the volumetric heat release rate $\dot{q}$ term. Therefore,

$\dot{\mathrm{p}} \approx(\gamma-1) \dot{\mathrm{q}}$

The volumetric heat release rate at crank angle $\theta$ may be written as

$$
\dot{\mathrm{q}}(\theta)=\frac{\operatorname{LHV}\left(\frac{\mathrm{m}_{\mathrm{f}}}{\mathrm{V}(\theta)}\right)}{\tau_{\text {reaction }}}
$$

where $V(\theta)$ is the cylinder volume and $\tau_{\text {reaction }}$ is the chemical reaction time scale. Thus

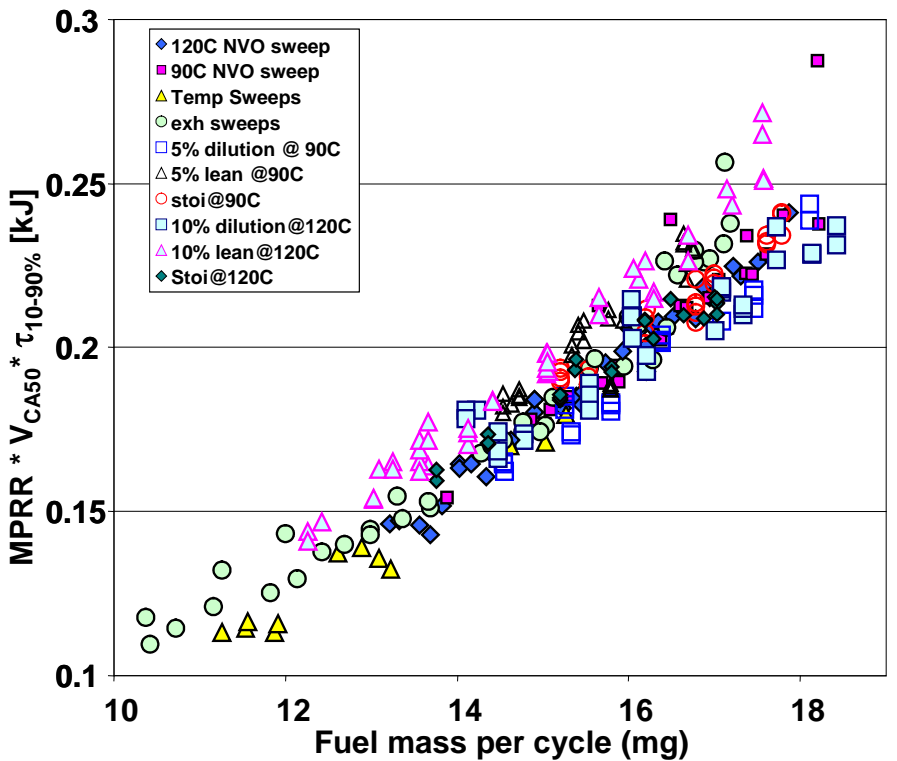

Fig. 18 Correlation plot of MPRR to engine combustion parameters.

$$
\operatorname{MPRR}=(\gamma-1)\left[\frac{\mathrm{m}_{\mathrm{f}} \mathrm{LHV}}{\mathrm{V}(\theta) \tau_{\text {reaction }}}\right]_{\max }
$$

To assess the validity of Eq. (9), we used the $10-90 \%$ burn duration as an estimate for $\tau_{\text {reaction }}$ and the volume at CA50 as estimate for the charge volume at the maximum pressure rise point.

The plot of MPRR $V_{C A 50} \tau_{10-90}$ versus the fuel mass, which, according to Eq. (9) should be a straight line, is shown in Fig. 18. This good correlation, which collapses the significantly scattered data in Fig. 10, supports the validity of the above simple thermodynamic model for MPRR. Thus Eq. (9) may be used to interpret the relationship of MPRR and boosting.

Since

$m_{f} L H V=\frac{N I M E P V_{D}}{\eta_{f, i}}$

whence

$\operatorname{MPRR}=(\gamma-1)\left[\frac{\text { NIMEP }}{\eta_{\mathrm{f}, \mathrm{i}}} \frac{\mathrm{V}_{\mathrm{D}}}{\mathrm{V}\left(\theta^{*}\right)}\right] \frac{1}{\tau_{\text {reaction }}}$

where $\mathrm{V}\left(\theta^{*}\right)$ is the cylinder volume at the MPRR point. With boosting to obtain a higher NIMEP, MPRR will increase proportionally if everything else remains the same. However, because ignition delay decreases with increase of charge density associated with boosting, the MPRR point will advance so that $\mathrm{V}\left(\theta^{*}\right)$ would be smaller; the efficiency $\eta_{f, i}$ will also be lower and thus increase the value of MPRR. (The above statement assumes that the nominal MPRR point is after TDC.) More significantly, if 
the charge is homogeneous and of fixed composition, reaction rate will increase (larger $1 / \tau_{\text {reaction }}$ ) with charge density. Then if the high load limit is constrained by MPRR, boosting will only make things worse.

To get out of the above conundrum, the opportunity is to relax the homogeneous charge condition and to let the composition change via the use of EGR. Regarding the former, it has been reported in the literature the use of direct injection $[6,11]$ and novel stratified EGR method [12] to produce charge stratification. Regarding the latter, the effect of EGR has been illustrated in Fig. 16. There is, however, the balance between suppression of MPRR and avoidance of misfiring in the trade off between EGR and boosting. That would be the subject of a later paper.

\section{CONCLUSION}

The combined effects of boosting, intake air temperature, trapped residual gas fraction, and dilution on the Maximum Pressure Rise Rate is investigated in a boosted single cylinder $\mathrm{HCCl}$ engine with combustion controlled by negative valve overlap. At the same NIMEP, dilution by EGR was found to be effective in lowering the MPRR; dilution by air, however, would increase the MPRR. A simple thermodynamic model, which was supported by the data, was used to relate the MPRR to the fuel mass and the reaction time. Using this model, if the reaction time did not change, MPRR would scale as NIMEP; thus if the high load limit is constrained by MPRR, boosting would not improve the output. This conundrum may be avoided if the reaction time could be slow down by stratification or by EGR.

\section{ACKNOWLEDGMENTS}

This research was funded by the US Department of Energy under a University Consortium on Low Temperature Combustion. The consortium members were MIT, U.C. Berkeley, U. of Michigan, and Stanford. The impact of boosting on NOx emission was the work by Nathan Anderson as part of his MS thesis [7].

\section{REFERENCES}

1. H. Santoso, J. Matthews and W. K. Cheng, "Managing $\mathrm{SI} / \mathrm{HCCl}$ Dual-Mode Engine Operation," SAE Paper 2005-01-0162, 2005.

2. Y. Urata, M. Awasaka, J. Takanashi, T. Kakinuma, T. Hakozaki and A. Umemoto, "A Study of GasolineFuelled $\mathrm{HCCl}$ Engine Equipped with an Electromagnetic Valve Train," 2004-01-1898.

3. J. Hyvönen, G. Haraldsson, B. Johansson, "Supercharging $\mathrm{HCCl}$ to Extend the Operating Range in a Multi-Cylinder VCR-HCCI Engine," SAE Paper 2003-01-3214, 2003.

4. D. Yap, M.L. Wyszynski, A. Megaritis, H. Xu, "Applying boosting to gasoline $\mathrm{HCCl}$ operation with residual gas trapping," SAE Paper 2005-01-2121, 2005

5. M. Sjöberg, J. E. Dec, "EGR and Intake Boost for Managing $\mathrm{HCCl}$ Low-Temperature Heat Release over Wide Ranges of Engine Speed," SAE Paper 2007-01-0051, 2007.

6. T. Johansson, B. Johansson, P. Tunestål, H. Aulin, "HCCl Operating Range in a Turbo-charged Multi Cylinder Engine with VVT and Spray-Guided DI," SAE Paper 2009-01-0494, 2009.

7. N. Anderson, "Examination of the High Load Limit of an $\mathrm{HCCl}$ Engine," MS thesis, Department of Mechanical Engineering, MIT, 2008.

8. P.E. Yelvington, W.H. Green, "Prediction of the Knock Limit and Viable Operating Range for a Homogeneous-Charge Compression-Ignition( $\mathrm{HCCl}$ ) Engine," SAE Paper 2003-01-1092, 2003.

9. J. A. Eng, "Characterization of Pressure Wave Oscillation in $\mathrm{HCCl}$ Combustion," SAE Paper 200201-2859, 2002.

10. M.M. Andreae, W.K. Cheng, T.Kenney, J. Yang, "On HCCI Knock," SAE Paper 2007-01-1858, 2007.

11. J. Kamio, T. Kurotani, K. Kuzuoka, Y. Kubo, H. Taniguchi, and K. Hashimoto, "Study on HCCl-SI Combustion Using Fuels Containing Ethanol," SAE Paper 2007-01-4051.

12. T.Kuboyama, Y. Moriyoshi, K. Hatamura, T. Yamada, J. Takanashi, "An Experimental Study of a Gasoline $\mathrm{HCCl}$ Engine Using the Blow-Down Super Charge System," SAE Paper 2009-01-0496, 2009.

\section{CONTACT}

Craig Wildman, c/o 31-153 MIT, Cambridge, MA 02139, cwildman@mit.edu

Robert J. Scaringe, c/o 31-153 MIT, Cambridge, MA 02139, cwildman@mit.edu

Prof. Wai Cheng, 31-165 MIT, Cambridge, MA 02139, wkcheng@mit.edu

\section{DEFINITIONS, ACRONYMS, ABBREVIATIONS}

$\begin{array}{ll}\text { a } & \text { velocity of sound } \\ \text { CAFE } & \text { Corporate Averaged Fuel Economy } \\ \text { EGR } & \text { Exhaust gas recirculation } \\ f & \text { Frequency } \\ \mathrm{HCCl} & \begin{array}{l}\text { Homogeneous-charge-compression- } \\ \text { ignition }\end{array} \\ & \text { Lower heating value } \\ \text { LHV } & \text { Manifold absolute pressure } \\ \text { MAP } & \text { Maximum Brake Torque } \\ \text { MBT } & \text { Maximum pressure rise rate } \\ \text { MPRR } & \text { Net indicated mean effective pressure } \\ \text { NIMEP } & \text { Noise-vibration-harshness } \\ \text { NVH } & \text { Number of moles } \\ \text { N } & \text { Partial Zero Emission Vehicle } \\ \text { PZEV } & \end{array}$




$\begin{array}{ll}\mathrm{x} & \text { Mole fraction } \\ \mathrm{R} & \text { Universal gas constant } \\ \mathrm{R}^{\star} & \text { R/molecular weight } \\ \mathrm{RI} & \text { Ringing index } \\ \mathrm{p} & \text { Pressure } \\ \dot{\mathrm{q}} & \text { Volumetric heat release rate } \\ \dot{\mathrm{Q}}_{\mathrm{L}} & \text { Total heat loss rate from charge } \\ \mathrm{T}_{\mathrm{i}} & \text { Intake mixture temperature } \\ \mathrm{V} & \text { Volume } \\ \beta & \text { Factor to relate pressure rise rate to } \\ \gamma & \text { acoustic pressure amplitude; see Table 2 } \\ \gamma & \text { Specific heat ratio } \\ \lambda & \text { Air equivalence ratio } \\ \eta_{\mathrm{fi}} & \text { Net indicated fuel conversion efficiency } \\ \tau_{\text {reaction }} & \text { Reaction time scale }\end{array}$

\section{APPENDIX}

The effect of dilution on MPRR versus NIMEP for the $120^{\circ} \mathrm{C}$ intake temperature MAP $=1.3 \mathrm{bar}$, and $10 \%$ external dilution case was discussed in the text. The results for $10 \%$ dilution at MAP $=1.5$ bar, and for $5 \%$ dilution at MAP = 1.2 and 1.3 bar are shown in the following figures. In all the cases, at the same NIMEP, MPRR decreased with dilution by EGR, and increased with dilution by air.

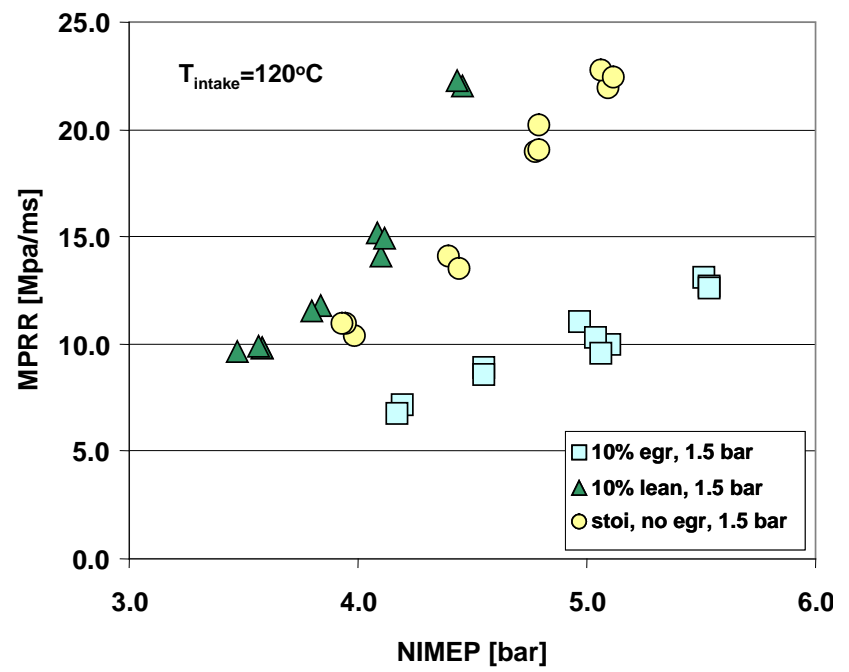

Fig. A1 MPRR versus NIMEP. Engine at $1500 \mathrm{rpm}$; MAP $=1.5$ bar; $. T_{i}=120^{\circ} \mathrm{C} ; \lambda=1.0$ for $10 \%$ EGR case; $\hat{1} \mathbf{s}=1.1$ for $10 \%$ lean case.

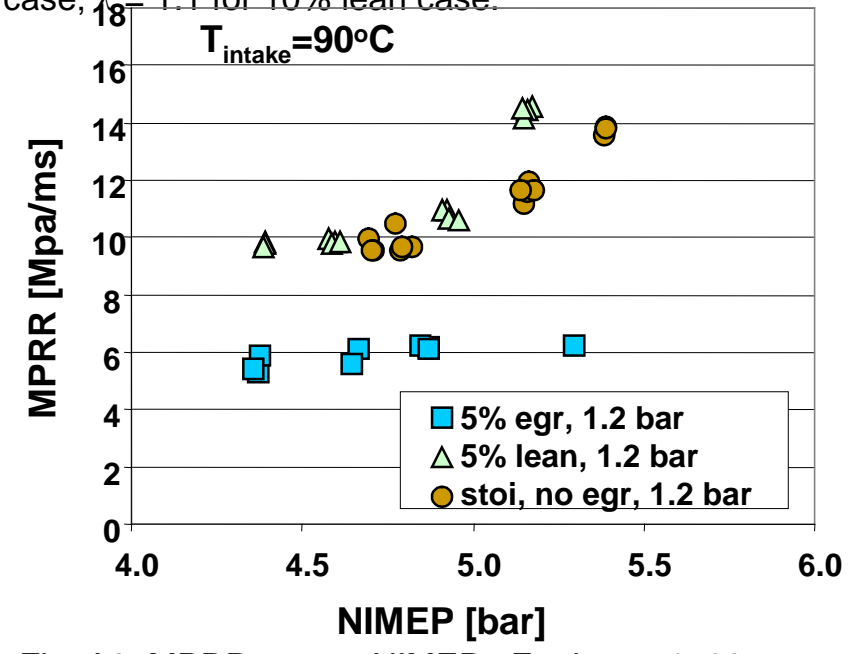

Fig. A2 MPRR versus NIMEP. Engine at $1500 \mathrm{rpm}$; MAP $=1.2$ bar; $. T_{i}=90^{\circ} \mathrm{C} ; \lambda=1.0$ for $10 \%$ EGR case; $\lambda=1.1$ for $10 \%$ lean case.

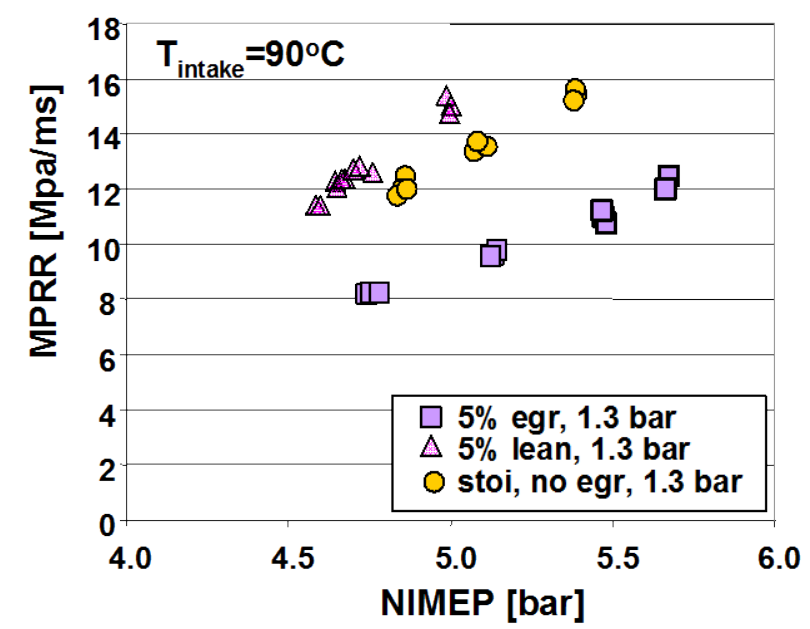

Fig. A3 MPRR versus NIMEP. Engine at $1500 \mathrm{rpm}$; MAP $=1.3$ bar; $. T_{i}=90^{\circ} \mathrm{C} ; \lambda=1.0$ for $10 \%$ EGR case; $\lambda=1.1$ for $10 \%$ lean case. 
